This item is the archived peer-reviewed author-version of:

\title{
Predictors of job seekers' self-disclosure on social media
}

\section{Reference:}

El Ouirdi Mariam, Segers Jesse, El Ouirdi Asma, Pais Ivana.- Predictors of job seekers' self-disclosure on social media Computers in human behavior - ISSN 0747-5632 - 53(2015), p. 1-12

Full text (Publisher's DOI): http://dx.doi.org/doi:10.1016/J.CHB.2015.06.039

To cite this reference: http://hdl.handle.net/10067/1264980151162165141 


\section{Predictors of Job Seekers' Self-Disclosure on Social Media}

Mariam El Ouirdi ${ }^{1 *}$, Jesse Segers ${ }^{1,2}$, Asma El Ouirdi ${ }^{1}$, Ivana Pais ${ }^{3}$

${ }^{1}$ Faculty of Applied Economics, University of Antwerp, Stadscampus Prinsstraat 13, S.B.216, 2000, Antwerpen, Belgium. (+32 326550 25)

${ }^{2}$ Antwerp Management School, Sint-Jacobsmarkt 9-13 / BE-2000 Antwerpen, Belgium. (+32 3 $2654758)$

${ }^{3}$ Università Cattolica del Sacro Cuore, largo Gemelli 1, 20123 Milano, Italy. (+39 3403367939) Mariam.ElOuirdi@student.uantwerpen.be; Jesse.Segers@ams.ac.be;

Asma.ElOuirdi@student.uantwerpen.be; Ivana.Pais@unicatt.it 


\title{
Predictors of Job Seekers' Self-Disclosure on Social Media
}

\begin{abstract}
Social media-based screening is a well-known practice to both recruiters and job seekers. Little is known, however, about how job seekers present themselves on social media, i.e. 'selfdisclosure', for employment purposes. This study builds on the theories of hyperpersonal computer-mediated communication, self-efficacy and social exchange to examine job seekers' professional online image concerns, social media self-efficacy, and perceptions of social media effectiveness in the job search as predictors of inappropriate and career-oriented self-disclosures on these media. Findings from a sample of 3374 Italian respondents showed that career-oriented self-disclosure was predicted by all three factors, whereas inappropriate self-disclosure was only predicted by social media self-efficacy. Furthermore, the relationship between professional online image concerns and inappropriate self-disclosure was moderated by age, education and work experience, but not by gender. Theoretical and practical implications are discussed, and directions for future research are suggested.
\end{abstract}

Keywords: Self-disclosure; social media; social recruiting; social exchange theory; self-efficacy; hyperpersonal computer-mediated communication 


\section{Predictors of Job Seekers' Self-Disclosure on Social Media}

\section{Introduction}

Social media and the Internet are widely used in the recruitment process, including for applicant screening. Recruiters use social and Internet technologies to access large amounts of information about job applicants with the purposes of avoiding negligent hiring (Slovensky \& Ross, 2012),

and discovering the applicant's real person instead of the excessively managed or deceptive self presented in conventional communications such as résumés and job interviews (Berkelaar, 2014). Recruiters continue to use social media in recruitment despite the perception of this practice as being socially irresponsible (Clark \& Roberts, 2010) and a violation of job seekers' privacy (Miller, Parsons, \& Lifer, 2010); its negative repercussions on organizational attraction and job seekers' intentions to litigate (Stoughton, Thompson, \& Meade, 2013); its association with several legal and ethical issues (Brown \& Vaughn, 2011; Davison, Maraist, \& Bing, 2011; Davison, Maraist, Hamilton, \& Bing, 2012; Ebnet, 2012; Elefant, 2011; Smith \& Kidder, 2010); and the questionable reliability and validity of information obtained from social media (Davison et al., 2011). On the other hand, job seekers know that their social media profiles are likely to be checked by prospective employers (Curran, Draus, Schrager, \& Zappala, 2014; Root \& McKay, 2014), and many even believe that recruiters have the right to check applicants' social media profiles in the recruitment process (Vicknair, Elkersh, Yancey, \& Budden, 2010). Despite this awareness, many job seekers commit a 'posting paradox' by sharing content they know is inappropriate to be viewed by potential employers (Miller et al., 2010). This paradoxical behavior raises a key question about the factors that predict job seekers' social media selfdisclosing behaviors, whether appropriate or inappropriate, especially in light of their awareness of their exposure to potential recruiters.

This study is aimed at examining the predictors of job seekers' self-disclosure on social media. Drawing on the theories of hyperpersonal computer-mediated communication (Walther, 1996), self-efficacy (Bandura, 1977) and social exchange (Cropanzano \& Mitchell, 2005), we examine the predictors of both inappropriate and career-oriented self-disclosures of job seekers on social media. The integration of these three theories is in line with existing self-disclosure models (e.g. Omarzu, 2000, and Misoch, 2015), which present this practice as a decision-making process dependent on a number of key factors. Among these factors, the present study takes into 
account three predictors in particular from the job seeker's perspective: (1) the motivation to keep a professional online image in the situational context of computer-mediated communication on social media, with the goals of developing one's online identity and gaining a recruiter's approval; (2) the personal trait of social media self-efficacy; and (3) the perceived effectiveness of social media in the job search, as a channel-related characteristic. Additionally, gender, age, education level, and work experience are all examined as moderators.

The present study fills several gaps in the literature. First, scholars have called for research on gender-based behavioral differences in self-disclosure on social media (Bateman, Pike, \& Butler, 2011; C.-W. Chang \& Heo, 2014), and on the impact of professional online image concerns on posting behavior (Miller, Salmona, \& Melton, 2012). Second, there has been a particular need to operationalize self-disclosure as an identity co-creation process (Hollenbaugh \& Ferris, 2014), a multidimensional construct (C.-W. Chang \& Heo, 2014), and in a qualitative way (Attrill, 2012). Third, research seems to be lacking on self-disclosure behaviors of job seekers in particular. The findings of this study provide practical insight regarding social media-based screening for recruiters, and on self-presentation and impression management for job seekers.

\section{Self-Disclosure}

Self-disclosure is defined as turning the unknown about oneself into shared knowledge (Joinson $\&$ Paine, 2007). This practice has become a fundamental communication phenomenon on the Internet (Jiang, Bazarova, \& Hancock, 2011), and a primary characteristic of computer-mediated communication (Joinson, 2001). Self-disclosure can be performed between pairs of people, within groups, or between an individual and an organization (Joinson \& Paine, 2007); and it can be voluntary on social media (Lee, Im, \& Taylor, 2008), elicited in marketing contexts (Moon, 2000), or imposed in commercial transactions.

Many antecedents are associated with self-disclosure on social media. This practice is positively associated with the need for popularity (Christofides, Muise, \& Desmarais, 2009; Christofides, Muise, \& Desmarais, 2012), limited awareness of the consequences of disclosure (Christofides et al., 2012), online profile visibility, online personal network size (Young \& Quan-Haase, 2009), and increased social media use (Chang \& Heo, 2014; Chang \& Hsiao, 2014). Empirical evidence also showed that bloggers, for example, voluntarily engage in self- 
disclosure for several reasons: maintaining self-presentation, managing relationships, keeping up with trends, storing and sharing information, seeking entertainment, and showing off (Lee et al., 2008). As a result, self-presentation and self-disclosure on social media can enhance the subjective well-being of their users (Kim \& Lee, 2011; Ko \& Kuo, 2009), and increase their feeling of connection (Utz, 2014).

Self-disclosure on social media is a co-creation process. This process involves the individual as well as his or her connections, as it includes both content disclosed by the user, and third-party contributions allowed by him or her to be viewed on his or her online profile. This cocreation results from the fact that identity is inherently a social process rather than a mere individual possession, and therefore comprises the individual's announcements in addition to placements made by others (Jackson II, 2010). Content disclosed by a user includes explicit identity announcements such as self-provided autobiographic descriptions, and implicit identity announcements in the form of impressions given off by the user (S. Zhao, Grasmuck, \& Martin, 2008). Identity claims, on Facebook for example, can further be categorized in three groups: (1) visual claims in the form of photos uploaded by the users themselves, or posted on their pages by others, and aiming to display the self as a social actor; (2) enumerative claims in the form of interests and preferences, and aiming to display the cultural self; and 3) narrative claims in the form of users' verbal descriptions of themselves (S. Zhao et al., 2008). Content posted by third parties includes comments and photo tagging (Labrecque, Markos, \& Milne, 2011). On Facebook, for example, friends shape one's online reputation (Trottier, 2012), and may even act as part of one's extended self (Belk, 2013).

Existing research on self-disclosure on social media seems limited. Previous studies seem often narrowly focused on a single website at a time, and primarily quantifies this practice by enumerating the number of items revealed on an online profile (e.g. Chang \& Heo, 2014; Special \& Li-Barber, 2012; Young \& Quan-Haase, 2009). Other studies, like Attrill's (2012), investigated self-disclosure with a qualitative approach, by examining individuals' beliefs, relationships, personal matters, interests and intimate feelings, across different Internet arenas. Given the need for further examination of not only the quantity, but also the quality, of disclosed information (Attrill, 2012), we will examine job seekers' self-disclosure on social media with a particular focus on two aspects: (a) one negative, with content deemed inappropriate for professional endeavors, referred to herein as 'inappropriate self-disclosure'; and (b) one positive, 
consisting of postings that are appropriate for professional audiences, referred to herein as 'career-oriented self disclosure'. These two facets of self-disclosure in the job-seeking context are further defined below.

Inappropriate Self-Disclosure. Defining inappropriate self-disclosure on social media is a challenging task. In a survey of medical schools, responding deans of student affairs reported unprofessional postings by students to include profanity, frankly discriminatory language, depiction of intoxication, and sexually suggestive material (Chretien, Greysen, Chretien, \& Kind, 2009). In an evaluation of public Facebook profiles of surgical residents, content deemed unprofessional included items displaying binge drinking, sexually suggestive photos and profanity, whereas making polarizing political and religious comments, wearing questionable attire, and holding guns while hunting were considered only potentially unprofessional (Langenfeld, Cook, Sudbeck, Luers, \& Schenarts, 2014). In other recruitment contexts, some recruiters pay attention to spelling and grammar mistakes, and unprofessional email addresses (Zide, Elman, \& Shahani-Denning, 2014). Other postings that are deemed inappropriate for professional contexts include any information that would be considered socially deviant in an employment interview setting (Newness, Steinert, \& Viswesvaran, 2012). Cognizant of the cocreation process involved on social media, some studies (e.g. Langenfeld et al., 2014) examined two components of unprofessional content on a person's profile: self-disclosed content by the individual, and viewable content on the individual's page even if submitted by others (e.g. photo tags, and comments made by friends). In the present study, inappropriate self-disclosure is defined as artifacts about an individual, shared on social media by himself/herself or his/her connections, and which would be considered unsuitable for a professional audience. These items can be thought of as the content that one would not normally include on a curriculum vitae.

Career-Oriented Self-Disclosure. Social media can be used for several professional purposes, such as personal branding, self-promotion and impression management (Chen, 2013; Jackson \& Lilleker, 2011; X. Zhao et al., 2013). In asynchronous exhibition spaces, such as social media, users submit different pieces of data or artifacts to engage in self-presentation (Hogan, 2010), and construct their personal brand identity (Labrecque et al., 2011). Some of the artifacts that social media users display as part of their branding and self-promotion are education, work 
experiences, abilities, personal achievements and qualifications, pictorial accounts of their social life, and their public conversations (Jackson \& Lilleker, 2011; Labrecque et al., 2011). In the employment context, recruiters assess various aspects of a job applicant's presence on social media like a digital résumé (Berkelaar, 2014). On LinkedIn, recruiters look for information including hobbies and/or interests that will allow them to connect with the applicant, a professional photograph, years of experience, number of connections, number of recommendations written for or by others, status updates, and skills and expertise (Zide et al., 2014). In the present study, career-oriented self-disclosure is defined as individual-related artifacts shared on social media for a professional audience. These items include the explicit identity claims usually made on a job seeker's curriculum vitae (e.g. autobiographic data, pictures, professional experience, awards and hobbies), as well as work-related placements made by others such as references and comments; and implicit identity statements such as the personality emerging from an applicant's profile.

\section{Theoretical Background}

Self-disclosure can be seen as a cognitive process impacting the ensuing content, depth, breadth and duration of the disclosure (Omarzu, 2000). According to Omarzu's (2000) model, individuals strategically manage their disclosures to control their social worlds and achieve social and personal goals. In this model, disclosure is a strategy for reaching one of five social goals, namely social approval, intimacy, relief of distress, identity clarification, and social control, in a specific situation, and towards a particular target (Omarzu, 2000). Furthermore, self-disclosure depends on two factors: the subjective utility of the possible reward, or the perceived value of the desired outcome; and the subjective probability of risk of the disclosure, such as social rejection and betrayal (Omarzu, 2000). As such, high subjective utility predicts greater amounts of disclosure, whereas high subjective risk predicts less depth in the disclosure (Omarzu, 2000). Applied to the employment context, this model suggests that self-disclosure is a strategy of selfpresentation and identity development on social media, driven by the desires to gain social approval, as the discloser aims to gain liking and social acceptance; and to obtain social control as the disclosure's target, i.e. the recruiter, has the power to bestow a reward or a benefit in the form of a job opportunity. Furthermore, subjective utility in this model pertains to career- 
oriented self-disclosure increasing a job seeker's chances at getting a job, whereas subjective risk pertains to inappropriate self-disclosure decreasing theses chances.

A more recent model summarizes the key factors that are expected to influence the occurrence of self-disclosure behavior on the Internet (see Misoch, 2015). In this model, five key factors are involved, namely: (1) the situation in which the communication occurs, such as a computer-mediated communicational situation; (2) the characteristics of the communication channel, such as the format of the disclosed content and audience size; (3) the motive behind the desire to self-disclose, such as the quest for a romantic relationship or self-expression; (4) personal characteristics and emotions, such as loneliness and life satisfaction; and (5) cultural criteria (Misoch, 2015). Additionally, two more factors are suggested to have potential impact on self-disclosure, namely gender and age (Misoch, 2015).

Combining both self-disclosure models, and building on relevant theoretical frameworks, we examine the impact of three factors on inappropriate and career-oriented self-disclosures, as follows: (1) the motivation to keep a professional online image in the situational context of social media use for employment, based on the hyperpersonal computer-mediated communication theory; (2) the personal trait of social media self-efficacy, based on self-efficacy theory; and (3) the perceived effectiveness of social media in the job search, as a channel-related characteristic, based on social exchange theory. Additionally, gender, age, education level, and work experience are all examined as moderators.

\subsection{Hyperpersonal Computer-Mediated Communication Theory}

People reveal different types of self-information in different Internet contexts (Attrill, 2012). Several theoretical frameworks attempt to explain why individuals disclose certain types of information. The hyperpersonal computer-mediated communication theory explains how this type of communication stimulates self-disclosure (Schouten, Valkenburg, \& Peter, 2007). This theory suggests that people can engage in an optimized self-presentation online (Attrill, 2012; Jiang et al., 2011), by selectively revealing attitudes and aspects of themselves in a controlled and socially desirable fashion (Walther, 2007). This behavior is supported by the affordances of computer-mediated communication, consisting of the ability to edit messages; the absence of time constraints for editing and composing messages; the composition of messages in physical isolation from the receiver, thus masking involuntary cues; and the reallocation of cognitive 
resources usually used to scan the environment and manage non-verbal cues in face-to-face communication towards the message composition (Walther, 2007).

Self-presentation on social media is associated with the user's desired image, be it professional or otherwise. Individuals who are concerned with presenting themselves favorably engage in more positive self-disclosure and are less inclined to reveal negative aspects about themselves (Gibbs, Ellison, \& Heino, 2006). In the employment context, students who were concerned about their privacy, and those who considered themselves to be on the labor market, were more concerned about their online image (Miller et al., 2012). On the other hand, students who aimed to portray a sexually appealing, wild, or offensive image were more likely to post problematic profile information (i.e. unsuitable content for a current or future work environment) on Facebook, compared to those who intended to appear intelligent and hard-working (Peluchette \& Karl, 2009). Therefore, we argue that, overall, job seekers will be motivated by the desire to convey a professional image to potential recruiters, and will consequently increase their career-oriented self-disclosure and decrease their inappropriate self-disclosure.

H1a. Professional online image concerns of job seekers have a negative relationship with their inappropriate self-disclosure on social media.

H1b. Professional online image concerns of job seekers have a positive relationship with their career-oriented self-disclosure on social media.

Additionally, we also expect gender, age, education level and work experience to trigger interaction effects between professional online image concerns and both types of self-disclosure.

Gender. Previous research showed gender differences in both types of online self-disclosure. In terms of generally and professionally accepted self disclosure, men were reportedly more likely to make their MySpace profiles visible to everyone (Tufekci, 2007), provide personal information on their LinkedIn profiles (Zide et al., 2014), post their contact information on Facebook (Special \& Li-Barber, 2012), share music pieces on Last.fm, a music discovery service (Putzke, Fischbach, Schoder, \& Gloor, 2014), and boast about their achievements and abilities on Twitter (Jackson \& Lilleker, 2011). Several explanations are found in previous research regarding the reasons behind the reduced online self-disclosure of women compared to men, one of which is increased privacy concerns (C.-W. Chang \& Heo, 2014). Other reasons that might 
discourage women from self-disclosure on social media include cyber misogyny with its several forms of gendered hatred, harassment, and abusive behavior directed towards females online (Bartlett, Norrie, Patel, Rumpel, \& Wibberley, 2014; West Coast LEAF, 2014). In terms of inappropriate self-disclosure, men tended to also post more problematic profile content, portray sexually appealing, wild, or offensive images of themselves on Facebook (Peluchette \& Karl, 2009), post more self-promoting and risqué pictures or comments on their profiles (Peluchette \& Karl, 2008), generate more alcohol-related content (Ridout, Campbell, \& Ellis, 2012), and use more swear words (Schwartz et al., 2013). Furthermore, male students were less concerned about employers accessing alcohol-related pictures and comments on their social networking profiles (Peluchette \& Karl, 2008). As a result, we expect that online professional concerns will lead to greater self-disclosure both in terms of inappropriate and career-oriented content for men compared to women.

H2a. There is an interaction effect between professional online image concerns and gender in the prediction of inappropriate self-disclosure, such that high professional online image concerns combined with the female gender lead to lower levels of inappropriate self-disclosure on social media.

H3a. There is an interaction effect between professional online image concerns and gender in the prediction of career-oriented self-disclosure, such that high professional online image concerns combined with the male gender lead to higher levels of career-oriented self-disclosure on social media.

Age. The association between job seekers' professional online image concerns and social media self-disclosure can also be impacted by age. In terms of inappropriate postings, freshmen were the most likely among college students to post inappropriate content (Miller et al., 2010), whereas older students were more likely to portray hardworking and intelligent images of themselves on their profiles (Peluchette \& Karl, 2009). Moreover, the older the students, that is the nearer they were to graduation, the more responsible approach they took to self-presentation on social media (Ness et al., 2013). This suggests that age may trigger an interaction effect in the relation between professional online concerns and both types of self-disclosure, in the sense that higher professional online concerns will be associated with less inappropriate self-disclosure and more career-oriented self-disclosure for older job seekers. 
H2b. There is an interaction effect between professional online image concerns and age in the prediction of inappropriate self-disclosure, such that high professional online image concerns combined with older age lead to lower levels of inappropriate self-disclosure on social media.

H3b. There is an interaction effect between professional online image concerns and age in the prediction of career-oriented self-disclosure, such that high professional online image concerns combined with older age lead to higher levels of career-oriented self-disclosure on social media.

Education. The education level of job seekers can trigger an interaction effect between their professional online image concerns and social media self-disclosure. A high level of education is associated with low levels of job satisfaction (Gazioglu \& Tansel, 2006), and low levels of organizational commitment, as highly educated individuals may have higher expectations from their organizations, or they may have a greater number of job options and be less likely to remain entrenched in one organization or position (Mathieu \& Zajac, 1990). For its part, organizational commitment is negatively correlated with turnover, and in particular with the intention to search for job alternatives, and the intention to leave one's job (Mathieu \& Zajac, 1990). Therefore, we argue that highly educated individuals will tend to be more dissatisfied with their jobs and less committed to their organization, and thus have higher intentions to look for other job options. This active job search mode might imply that highly educated individuals are constantly concerned about their online professional image. We thus hypothesize that the professional concerns of highly educated individuals will lead to lower levels of inappropriate postings and higher levels of career-oriented self-disclosure.

H2c. There is an interaction effect between professional online image concerns and education level in the prediction of inappropriate self-disclosure, such that high professional online image concerns combined with higher levels of education lead to lower levels of inappropriate selfdisclosure on social media.

H3c. There is an interaction effect between professional online image concerns and education level in the prediction of career-oriented self-disclosure, such that high professional online image concerns combined with higher levels of education lead to higher levels of career-oriented selfdisclosure on social media. 
Work Experience. The work experience of job seekers is also expected to moderate the relationship between their professional online image concerns and their social media selfdisclosure. Early stage professionals have strong concerns about the blurring boundaries between their private lives and their professional personae on social media (Kirwan \& Mc Guckin, 2013). As early stage professionals start observing reputational damage to their images on social media, many take action (Kirwan \& Mc Guckin, 2013). When faced with threats to their professional reputation, such as offensive comments on a Facebook group they were members of, some professionals take action by withdrawing from that group (Kirwan \& Mc Guckin, 2013). This suggests a paradigm shift in individuals' perceptions of their professional image as they start their careers, compared to when they were students or inexperienced job seekers. Therefore, we expect that professional online concerns will further decrease inappropriate self-disclosure and increase career-oriented self-disclosure for individuals with more work experience.

H2d. There is an interaction effect between professional online image concerns and work experience in the prediction of inappropriate self-disclosure, such that high professional online image concerns combined with high levels of work experience lead to lower levels of inappropriate self-disclosure on social media.

H3d. There is an interaction effect between professional online image concerns and work experience in the prediction of career-oriented self-disclosure, such that high professional online image concerns combined with higher levels of work experience lead to higher levels of careeroriented self-disclosure on social media.

\subsection{Self-Efficacy Theory}

Developed by Bandura (1977), self-efficacy is both a theory in itself, and a construct of social cognitive theory (Bandura, 2001). Self-efficacy is a measure of an individual's perception of his or her ability to perform a specific behavior, rather than a measure of actual skills (Hsu \& Chiu, 2004; Wrench \& Punyanunt-Carter, 2007). In computer-mediated communication research, two main types of self-efficacy were discussed: computer self-efficacy, as the extent to which an individual perceives he or she can use a specific computer technology; and Internet self-efficacy, as the extent to which an individual perceives he or she can use the Internet (Hsu \& Chiu, 2004; Wrench \& Punyanunt-Carter, 2007). With the present study's emphasis on social media, social media self-efficacy is defined as the individual's belief in his or her ability to use social media, 
and his or her perceived ability to reach desired outcomes on social media (Hocevar, Flanagin, \& Metzger, 2014).

Based on self-efficacy theory, individuals who perceive themselves as possessing abilities to use social media are more likely to use these tools. Empirically, behavioral intention or attitude towards a technology, its adoption, and its actual use are associated with feeling efficacious about it (Gangadharbatla, 2008; Hsu \& Chiu, 2004); and having social media skills is positively correlated with both private and professional use of these tools (Moreno, Navarro, Tench, \& Zerfass, 2015). Moreover, the more people used social media, the more information they disclosed (C.-W. Chang \& Heo, 2014). However, with increased social media activity, comes the risk of posting content that will be deemed inappropriate in employment contexts. Over-sharing is the result of a disinhibition effect that makes people loosen up, feel less restrained, and express themselves more openly (Suler, 2004). The use of Internet media that may lack certain nonverbal cues, such as visual and auditory cues, makes users feel less constrained to engage in self-disclosure and self-presentation online (Schouten et al., 2007). Therefore, the more users feel disinhibited, the more they engage in online self-disclosure, due to the reduced nonverbal cues and controllability in online settings such as instant messaging (Schouten et al., 2007). Consequently, we hypothesize the following:

H4a: Social media self-efficacy of job seekers has a positive relationship with inappropriate selfdisclosure on social media.

H4b: Social media self-efficacy of job seekers has a positive relationship with career-oriented self-disclosure on social media.

\subsection{Social Exchange Theory}

Disclosure has been examined in previous research as a medium for social exchange (Omarzu, 2000). Social exchange theory is one of the most influential conceptual paradigms in organizational behavior, with roots dating back to at least the 1920s (Cropanzano \& Mitchell, 2005). The basic tenets of social exchange theory are that parties a) abide by certain rules of exchange, including reciprocity; b) exchange resources, including information; and c) form certain social exchange relationships (Cropanzano \& Mitchell, 2005). On social media, the social relationship formed between a user and the platform itself, or its community, is governed by a social contract which is usually summarized explicitly in the terms of use (Snyder, Carpenter, \& 
Slauson, 2007), or formed informally and implicitly as social etiquette (Smith \& Kidder, 2010). In this social relationship, several social benefits and costs come to play from the user's perspective. On Facebook, for example, the pay off for using this social network is convenience, and staying in touch with friends, acquaintances and co-workers; whereas the cost for nonparticipation is social exclusion and a lack of online identity (Raynes-Goldie, 2010; Trottier, 2012). In terms of self-disclosure in particular, a social contract implies that individuals choose to disclose personal information when they perceive the existence of a certain benefit in exchange (C.-W. Chang \& Heo, 2014). Users can trade providing personal information for the advantage of technology benefits (Joinson \& Paine, 2007), and tend to increase their disclosure of basic and sensitive information with the increased perception of social media benefits (C.-W. Chang \& Heo, 2014) or usefulness (Shibchurn \& Yan, 2015). In employment, recruiters emphasize a new transparency imperative consisting of the expectation of proactive information provision from job applicants, as lack of information would be viewed negatively (Berkelaar, 2014). This can be seen as a minimum disclosure cost, suggested as a cultural norm related to a commonly expected level of participation on social media (Tufekci, 2007). In other words, when one uses social media, one is usually expected to display a certain level of self-definition, especially during a job search. Therefore, we hypothesize that job seekers perceiving social media to be useful in their job search will disclose more career-oriented information on their profiles, and share less inappropriate postings.

H5a. The perceived effectiveness of social media in the job search by job seekers has a negative relationship with inappropriate self-disclosure on social media.

H5b. The perceived effectiveness of social media in the job search by job seekers has a positive relationship with career-oriented self-disclosure on social media.

In summary, we expected inappropriate and career-oriented self-disclosures of job seekers to be related to their professional online image concerns, social media self-efficacy, and perceived effectiveness of social media in the job search. These expected associations are illustrated in Figure 1, along with the hypothesized moderating effects of gender, age, education level, and work experience.

Figure 1. Research Model of the Predictors of Job Seekers' Self-Disclosure on Social Media 


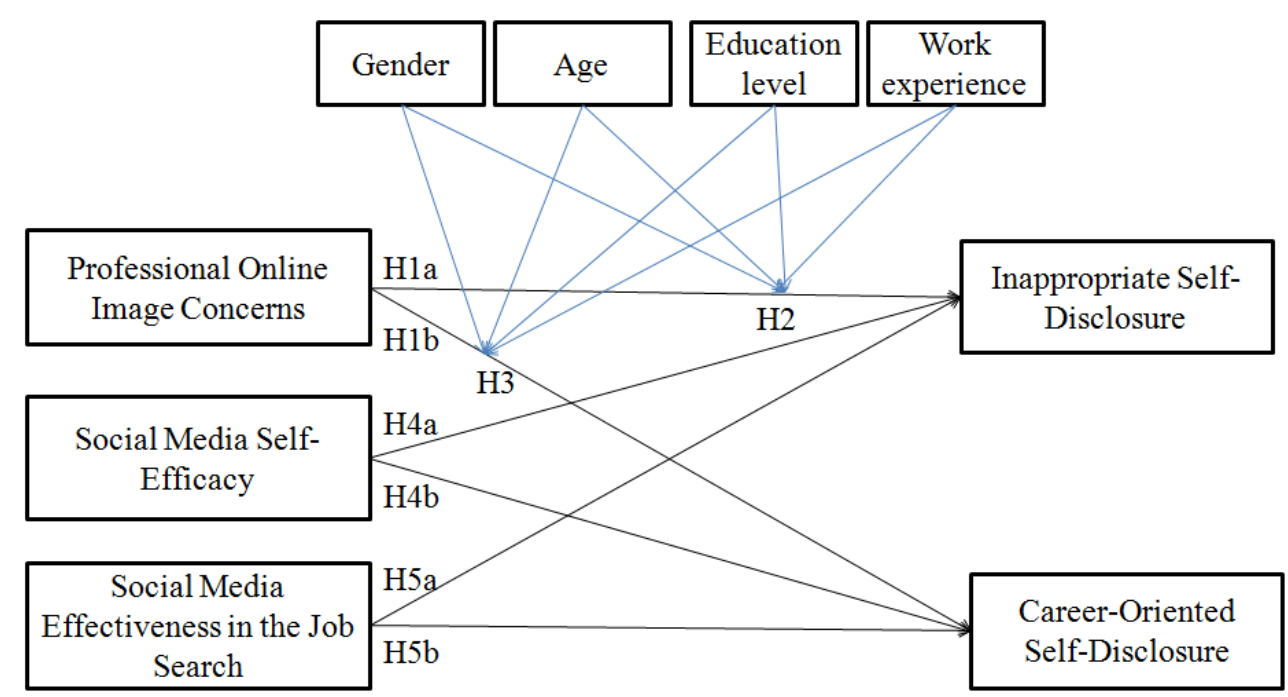

\section{Methodology}

\subsection{Procedure and Sample}

Data collection for this study was part of a large social recruiting and job seeking research project, conducted in collaboration with an international human resources consulting firm. The online questionnaire designed for job seekers was pre-tested with two job seekers, and further validated by the firm's managers. During this test of practicality, the measurement instrument was judged in terms of economy, convenience, and interpretability (Kothari, 2011). For convenience reasons, and to limit the time it takes to participate in the study, the length of the survey was shortened as a result of the pre-testing. The final survey instrument consisted of a total of 28 rating-scale and multiple-choice questions. The relevant questions for this study pertained to social media use and perceived effectiveness in the job search, posting behaviors and professional online image concerns, and demographic information. The survey was created and hosted on Qualtrics, an online survey software, and a web link was distributed between March and June, 2014 through the firm's mailing list and online social networks. Participation was voluntary and anonymous.

Italian employed and non-employed job seekers were the target population of this study for two reasons. First, with the growing use of social media-based screening, recruiters are increasingly expecting job seekers to curate a digital career capital by making their employability more digitally visible (Berkelaar \& Buzzanell, 2014). This expectation transcends the temporary boundary of the job search phase and extends along an individual's professional career, thus 
making the use of a diversified sample of employed as well as non-employed job seekers, including students and non-students, particularly relevant. Second, the focus on Italian job seekers is timely, as the country's unemployment rate has increased to 13.4 percent in November 2014, compared to 12.5 percent a year earlier (Eurostat, 2015). The rate of youth unemployment, in particular, in Italy in the same period was 43.9 percent, making it the fourth highest rate in the European Union (Eurostat, 2015). Therefore, by having one of the largest job seeker populations in Europe, Italy represents a suitable target for this study as the findings can be of practical use for both recruiters and job seekers.

A sample of 3374 complete responses from Italian job seekers was retained for this study (see Table 1). The sample was composed of 53.3 percent of male job seekers, and included 40.9 percent of individuals born after 1981, 44.6 percent born between 1965 and 1980, and 14.4 percent born before 1964. The respondents had varying levels of education and work experience, with the majority having at least a high school degree and at least 2 years of experience. Finally, 66.2 percent of all respondents were unemployed and looking for a job at the time of completing the survey.

Table 1. Demographic Profile of Respondents (N=3374)

\begin{tabular}{llcc}
\hline Variable & Descriptive & Frequency & Percentage \\
\hline Gender & Female & 1576 & 46,7 \\
Age & Male & 1798 & 53,3 \\
& Before 1964 & 487 & 14,4 \\
& $1965-1980$ & 1506 & 44,6 \\
Highest level of education & After 1981 & 1381 & 40,9 \\
& Less than High School & 443 & 13,1 \\
& High School & 1636 & 48,5 \\
& Some College & 370 & 11,0 \\
& 2- or 3-Year College Degree & 683 & 20,2 \\
Years of work experience & 4-Year College Degree or More & 242 & 7,2 \\
& 1 year or less & 443 & 13,1 \\
& 2 years & 269 & 8,0 \\
& 3-5 years & 547 & 16,2 \\
& 6-10 years & 629 & 18,6 \\
& 11-20 years & 761 & 22,6 \\
& 20 years or more & 725 & 21,5 \\
Employment status & Employed & 1140 & 33,8 \\
& Unemployed & 2234 & 66,2 \\
\hline
\end{tabular}

\subsection{Measures}


Most measures used in this tudy built on existing scales or were inspired by empirical findings from relevant studies (see Appendix A). As all used scales had more than two items, reliability was assessed using Cronbach's (1951) coefficient alpha, which is a suitable measure for this type of scales, as opposed to the Pearson correlation which is adequate for one-item scales, and the Spearman-Brown coefficient which is more appropriate for two-item scales (Eisinga, Grotenhuis, \& Pelzer, 2013). All scales displayed satisfying reliability levels.

Inappropriate Self-Disclosure. This construct was assessed with four items inspired by the problematic profile information items' list and the faux pas scale suggested by Peluchette and Karl (2009), and Karl, Peluchette, and Schlaegel (2010). Together, these lists originally amounted to ten distinctive items, six of which were image-based, namely self-photo in the nude, self-photo with sexual props, self-photo with firearms, self-photo semi-nude, self-photo (sexy or provocative), self-photo drinking alcohol; and four were textual, namely comments regarding the use of illegal drugs, comments regarding participation in activities which are in violation of university policy, comments regarding sexual activities or sexual preferences, and comments regarding personal use of alcohol. In the present study, respondents were asked to assess the likelihood of posting two image-based items (informal selfie or tagged photo, and controversial selfie/tagged photo) and two textual items (comments on controversial topics, and comments on participation in activities which are in violation of university or workplace policy) on their profiles. Responses on a 5-point scale from 1 (not at all) to 5 (a lot) were averaged into an inappropriate self-disclosure index, with Cronbach's $\alpha=0.712$.

Career-Oriented Self-Disclosure. Respondents were asked to assess, on a scale ranging from 1 (not at all) to 5 (a lot), the amount of career-related information that their social media profile contained. This construct's measurement was inspired by the results of the exploratory study of Zide et al. (2014), and contained nine items including professional experience and number of contacts. Responses were averaged into a career-oriented self-disclosure index, with Cronbach's $\alpha=0.910$.

Professional Online Image Concerns. On a scale ranging from 1 (I strongly disagree) to 7 (I strongly agree), respondents rated their agreement with three statements, "It is important to 
maintain a professional image online", "I work hard to maintain a professional image in my profile" and "My online image is important to my future". This scale is a shortened version of the 5-item professional online image concerns scale developed by Miller, Salmona, and Melton (2012). Responses were averaged into a professional online image concerns' index, with Cronbach's $\alpha=0.891$.

Social Media Self-Efficacy. To measure a respondent's belief in being able to use social media, we adapted a shorter version of the Internet self-efficacy scale developed by Kim and Glassman (2013) to the social media context. The respondents indicated on a scale going from 1 (not at all confident), to 7 (very confident), how confident they were that they could perform six tasks. Items included statements such as "I can be very effective using social media", "I can find important and interesting information by reading other people's content on social media", and "I can communicate very effectively using social media". Responses were averaged into a social media self-efficacy index, with Cronbach's $\alpha=0.929$.

Social Media Effectiveness in the Job Search. With no existing scales to measure this variable, we asked respondents to rate the effectiveness of 11 social media platforms, including Facebook, LinkedIn and Twitter, in their job search on a scale ranging from 1 (very ineffective) to 5 (very effective). Responses were averaged into a social media effectiveness index, with Cronbach's $\alpha=$ 0.929 .

Control Variables. Five variables were included as control and/or moderator variables: gender, age, education level, work experience, and employment status. The age groups were coded as 1 for people born 'before 1964', 2 for '1965-1980' and 3 for 'after 1981'. Education options were 'less than high school' (1), 'high school' (2), 'some college' (3), '2 or 3-year college degree' (4), '4-year college degree or more' (5). Years of work experience varied between '1 year or less' (1), '2 years' (2), '3-5 years' (3), '6-10 years' (4), '11-20 years' (5), and '20 years or more' (6). Employment status and gender were coded as dichotomous variables with 1 for 'employed' and 2 for 'unemployed'; 1 for 'female' and 2 for 'male'.

\section{Findings}




\subsection{Descriptive Statistics}

Results indicated that responding job seekers had a higher tendency to share professional content than to share inappropriate postings on their social media profiles. On 5-point scales, respondents had the mean scores of $1.59(\mathrm{SD}=.70)$ in inappropriate self-disclosure, and $3.12(\mathrm{SD}=1.01)$ in career-oriented self-disclosure (Table 2). On 7-point scales, respondents reported having above average professional online image concerns $(\mathrm{M}=4.24 ; \mathrm{SD}=1.94)$ and beliefs in their social media abilities $(\mathrm{M}=4.20 ; \mathrm{SD}=1.54)$. The mean score for social media effectiveness in the job search based on 11 platforms, and assessed on a 5-point scale, was 2.51 ( $\mathrm{SD}=.80)$. Given the large sample size, significance levels were set at 0.01 for all analyses.

Table 2. Parametric Correlation Matrix and Descriptive Statistics

\begin{tabular}{|c|c|c|c|c|c|c|c|c|c|c|c|c|}
\hline & Mean & SD & 1 & 2 & 3 & 4 & 5 & 6 & 7 & 8 & 9 & 10 \\
\hline 1. Inappropriate self-disclosure & 1,59 & ,70 & 1,00 & & & & & & & & & \\
\hline 2. Career-oriented self-disclosure & 3,12 & 1,01 &, $19^{* *}$ & 1,00 & & & & & & & & \\
\hline 3. Professional online image concerns & 4,24 & 1,94 &, $13^{\star *}$ &, $32^{* *}$ & 1,00 & & & & & & & \\
\hline 4. Social media self-efficacy & 4,20 & 1,54 &, $27^{* *}$ &, $42^{* *}$ &, $44^{\star *}$ & 1,00 & & & & & & \\
\hline 5. Social media effectiveness & 2,51 &, 80 &, $06^{* *}$ &, $17^{* *}$ &, $14^{* *}$ &, $24^{* *}$ & 1,00 & & & & & \\
\hline 6. Gender & & & 02 &, $05^{*}$ &,$- 07^{\star *}$ &,- 04 &,$- 08^{* *}$ & 1,00 & & & & \\
\hline 7. Age & & &, $19^{* *}$ &, 01 &, $08^{* \star}$ &, $15^{\star \star}$ &,- 04 &,$- 15^{\star *}$ & 1,00 & & & \\
\hline 8. Education level & & & 00 &, $05^{*}$ &, $12^{\star *}$ &, $15^{* \star}$ & 01 &,$- 14^{* *}$ &, $16^{\star *}$ & 1,00 & & \\
\hline 9. Work experience & & &,$- 16^{* *}$ &, 04 &,$- 09^{* *}$ &,$- 13^{* *}$ &, 01 &, $16^{* *}$ &,$- 71^{* *}$ &,$- 22^{* *}$ & 1,00 & \\
\hline 10. Employment status & & &,- 01 &, 00 & , 00 &,- 04 & ,03 &,- 03 &,- 01 &,$- 23^{* *}$ &,$- 13^{* *}$ & 1,00 \\
\hline
\end{tabular}

Note. ${ }^{*} \mathrm{p}<.01 ;{ }^{* \star} \mathrm{p}<.001 ; \mathrm{N}=3374$

Preliminary analyses were performed to ensure that the assumptions of normality, linearity and homoscedasticity were not violated. Moreover, to ensure that the dataset did not suffer from common method variance, separate principal component analyses were conducted with Varimax rotations on all scales. The values of the Kaiser-Meyer-Olkin measure of sampling were greater than the required 0.6 for all scales $(0.903,0.681,0.738,0.865$ and 0.939 respectively for career-oriented self disclosure, inappropriate self-disclosure, professional online image concerns, social media self-efficacy, and social media effectiveness).

Correlations were conducted on all independent, dependent, and control variables. Bivariate relationships were assessed using Pearson's correlation coefficient. Significance level was less than 0.001 for all relationships of interest for this study. In the associations between the independent and dependent variables, the strongest correlations were between social media self- 
efficacy and career-oriented self-disclosure $(\mathrm{r}=.42, \mathrm{p}<.001)$, followed by the correlations between professional online image concerns and career-oriented self-disclosure $(r=.32, p<.001)$, and between social media self-efficacy and inappropriate self-disclosure $(r=.27, p<.001)$. The weakest correlations were between social media effectiveness and inappropriate self-disclosure $(\mathrm{r}=.06, \mathrm{p}<.001)$, professional online image concerns and inappropriate self-disclosure $(\mathrm{r}=.13$, $\mathrm{p}<.001)$, and social media effectiveness and career-oriented self-disclosure $(r=.17, \mathrm{p}<.001)$.

\subsection{Hierarchical Multiple Regression}

To test hypotheses 1, 4 and 5 positing the impact of professional online image concerns, social media self-efficacy and social media effectiveness on inappropriate and career-oriented selfdisclosure behaviors, we performed three series of hierarchical linear regression analyses. For each analysis, the control variables, namely gender, age, level of education, work experience, and employment status were entered first to account for their influence on each type of selfdisclosure. Next, all independent variables, namely professional online image concerns, social media self-efficacy and social media effectiveness in the job search, were tested on each one of the two outcome variables.

Inappropriate Self-Disclosure. The control variables alone explained only 4 percent of the variance in inappropriate self-disclosure (Table 3). After inclusion of the three independent variables, the model as a whole explained 10 percent of the variance in inappropriate selfdisclosure, thus leading to an increase of 6 percent in adjusted $\mathrm{R}^{2}$. The model summary indicated that this was a significant contribution with $\mathrm{F}(8,3365)=49.038, \mathrm{p}<.001$. The coefficients' table indicated that no significant contributions were brought to this model by work experience, employment status, professional online image concerns, and social media effectiveness. Inappropriate self-disclosure was best predicted by social media self-efficacy $(\beta=.24, \mathrm{p}<.001)$, age $(\beta=.13, \mathrm{p}<.001)$, education $(\beta=-.07, \mathrm{p}<.001)$, and gender $(\beta=.05, \mathrm{p}<.01)$. These findings supported H4a, but provided no support for H1a and H5a.

Table 3. Hierarchical Regression Models for Inappropriate Self-Disclosure and Career-Oriented Self-Disclosure 


\begin{tabular}{|c|c|c|c|c|c|c|c|c|c|}
\hline & & Beta & Beta & Beta & Beta & Beta & Beta & Beta & Beta \\
\hline \multirow[t]{6}{*}{ Step 1} & Gender &, $048^{*}$ &, $048^{*}$ &, $048^{*}$ &, $048^{*}$ &, $061^{\star *}$ &, $061^{\star *}$ &, $061^{* *}$ &, $061^{* *}$ \\
\hline & Age &, $159^{\star \star}$ &, $159^{* *}$ &, $159^{* *}$ &, $159^{\star \star}$ &, $092^{* *}$ &, $092^{* *}$ &, $092^{* *}$ &, $092^{* *}$ \\
\hline & Education level &,- 044 &,- 044 &,- 044 &,- 044 &, $078^{\star *}$ &, $078^{* *}$ &, $078^{* *}$ &, $078^{* *}$ \\
\hline & Work experience &,- 064 &,- 064 &,- 064 &,- 064 &, $118^{\star \star}$ &, $118^{* *}$ &, $118^{* *}$ &, $118^{* \star}$ \\
\hline & Employment status &,- 024 &,- 024 &,- 024 &,- 024 & ,033 &, 033 &, 033 &, 033 \\
\hline & Adjusted $\mathrm{R}^{2}$ &, $040^{\star *}$ &, $040^{* *}$ &, $040^{* *}$ &, $040^{\star *}$ &, $011^{\star *}$ &, $011^{* *}$ &, $011^{* *}$ &, $011^{\star *}$ \\
\hline \multirow[t]{9}{*}{ Step 2} & Gender &, $052^{*}$ &, $052^{*}$ &, $052^{*}$ &, $052^{*}$ &, $076^{\star \star}$ &, $076^{\star *}$ &, $076^{\star \star}$ &, $076^{* \star}$ \\
\hline & Age &, $133^{\star *}$ &, $133^{* *}$ &, $133^{\star \star}$ &, $133^{\star \star}$ & 055 &, 055 &, 055 &, 055 \\
\hline & Education level &,$- 075^{\star *}$ &,$- 075^{\star \star}$ &,$- 075^{\star *}$ &,$- 075^{\star \star}$ &, 019 &, 019 &, 019 &, 019 \\
\hline & Work experience &,- 055 &,- 055 &,- 055 &,- 055 &, $136^{\star *}$ &, $136^{* *}$ &, $136^{* *}$ &, $136^{* *}$ \\
\hline & Employment status &,- 022 &,- 022 &,- 022 &,- 022 & ,032 &, 032 &, 032 &, 032 \\
\hline & Professional online image concerns &, 021 & ,021 &, 021 & ,021 &, $176^{\star \star}$ &, $176^{* *}$ &, $176^{* *}$ &, $176^{* \star}$ \\
\hline & Social media self-efficacy &, $243^{\star *}$ &, $243^{\star \star}$ &, $243^{\star *}$ &, $243^{\star \star}$ &, $335^{\star \star}$ &, $335^{\star *}$ &, $335^{\star *}$ &, $335^{\star \star}$ \\
\hline & Social media effectiveness &, 012 & ,012 &, 012 & 012 &, $068^{* *}$ &, $068^{\star *}$ &, $068^{* *}$ &, $068^{* *}$ \\
\hline & Adjusted $\mathrm{R}^{2}$ &, $102^{* *}$ &, $102^{* \star}$ &, $102^{* \star}$ &, $102^{* *}$ &, $217^{* \star}$ &, $217^{* \star}$ &, $217^{* \star}$ &, $217^{\star \star}$ \\
\hline \multirow[t]{13}{*}{ Step 3} & Gender &,- 016 & $053^{*}$ &, $050^{\star}$ &, $054^{\star \star}$ & ,039 &, $075^{\star *}$ &, $075^{\star *}$ &, $075^{\star \star}$ \\
\hline & Age &, $133^{\star *}$ &, $264^{\star \star}$ &, $133^{\star \star}$ &, $133^{\star \star}$ & ,055 &,- 005 &, 055 &, 055 \\
\hline & Education level &,$- 073^{* *}$ &,$- 073^{* *}$ & ,025 &,$- 073^{\star *}$ & , 020 &, 018 &, 065 &, 018 \\
\hline & Work experience &,- 054 &,- 059 &,- 055 &,$- 211^{\star *}$ &, $137^{\star \star}$ &, $138^{* *}$ &, $136^{* *}$ &, $213^{* *}$ \\
\hline & Employment status &,- 021 &,- 021 &,- 022 &,- 022 & ,033 &, 032 & 032 &, 032 \\
\hline & Professional online image concerns &,- 074 &, $215^{\star *}$ &, $117^{*}$ &,$- 157^{\star *}$ & ,124 &, 086 & ,220** &, $263^{* *}$ \\
\hline & Social media self-efficacy &, $242^{* *}$ &, $245^{* *}$ &, $242^{* *}$ &, $243^{\star *}$ &, $334^{* *}$ &, $334^{* *}$ &, $334^{* *}$ &, $335^{* *}$ \\
\hline & Social media effectiveness & 011 & 013 &, 013 & 013 &, $067^{\star \star}$ &, $067^{* *}$ &, $068^{* *}$ &, $067^{\star *}$ \\
\hline & Professional online image concerns*Gender &, 117 & & & & ,064 & & & \\
\hline & Professional online image concerns ${ }^{*}$ Age & &,$- 254^{* *}$ & & & &, 116 & & \\
\hline & Professional online image concerns ${ }^{*}$ Education level & & &,$- 153^{*}$ & & & &,- 071 & \\
\hline & Professional online image concerns ${ }^{*}$ Work experience & & & &, $236^{* *}$ & & & &,- 116 \\
\hline & Adjusted $\mathrm{R}^{2}$ &, $103^{\star \star}$ &, $106^{\star \star}$ &, $104^{\star *}$ &, $107^{\star \star}$ &, $217^{\star \star}$ &, $217^{\star \star}$ &, $217^{\star \star}$ & ,218** \\
\hline
\end{tabular}

Note. ${ }^{*} \mathrm{p}<.01 ;{ }^{* *} \mathrm{p}<.001 ; \mathrm{N}=3374$

Career-Oriented Self-Disclosure. The control variables explained only 1 percent of the variance in career-oriented self-disclosure. After inclusion of the three independent variables, the model as a whole explained 22 percent of the variance in career-oriented self-disclosure, thus leading to an increase of 21 percent in adjusted $\mathrm{R}^{2}$. The model summary indicated that this was a significant contribution with $\mathrm{F}(8,3365)=117.590, \mathrm{p}<.001$. The best predictor of career-oriented selfdisclosure was social media self-efficacy $(\beta=.33, \mathrm{p}<.001)$, followed by professional online image concerns $(\beta=.18, p<.001)$, work experience $(\beta=.14, p<.001)$, gender $(\beta=.08, p<.001)$, and social media effectiveness $(\beta=.07, \mathrm{p}<.001)$. Age, education level, and employment status did not prove to be significant predictors. These findings supported $\mathrm{H} 1 \mathrm{~b}, \mathrm{H} 4 \mathrm{~b}$, and $\mathrm{H} 5 \mathrm{~b}$.

\subsection{Interaction Effects}


Moderation analyses were performed following Baron and Kenny's (1986) procedure, to examine whether the relationships between professional online image concerns and each type of self-disclosure changed in function of gender, age, education level and work experience. First, for each hypothesis, we examined the coefficient of the product of the independent variable and the moderator after controling for all other control and predictor variables, and noted its test of significance in a hierarchical regression analysis (Table 3). The moderation models involving professional online image concerns and career-oriented self disclosure by gender, age, education level and work experience were not significant, thus providing no support for $\mathrm{H} 3 \mathrm{a}, \mathrm{H} 3 \mathrm{~b}, \mathrm{H} 3 \mathrm{c}$, and $\mathrm{H} 3 \mathrm{~d}$. The moderation models involving professional online image concerns and inappropriate self-disclosure were significant for age $(\mathrm{p}<.001)$, education level $(\mathrm{p}<.01)$ and work experience $(\mathrm{p}<.001)$, but not for gender, thus providing no support for $\mathrm{H} 2 \mathrm{a}$. Second, to further test the hypotheses $\mathrm{H} 2 \mathrm{~b}, \mathrm{H} 2 \mathrm{c}$ and $\mathrm{H} 2 \mathrm{~d}$, moderation analyses were performed using Hayes's (2012) computational tool 'PROCESS'. For each hypothesis, we ran a model for the moderator variable with all control and predictor variables as co-variates. To interpret the direction of the detected moderations, the pick-a-point approach in the Johnson-Neyman technique was used, which mathematically derives the points along the continuum of the moderator where the effect of the focal predictor transitions between statistically significant and non-significant (Hayes \& Matthes, 2009). The results were as follows:

Age. $\mathrm{H} 2 \mathrm{~b}$ was only significant for age scores equal to or below 1.80 ( $\mathrm{p}<.01)$. In other words, this interaction effect was significant for all respondents born before 1964 and most respondents born between 1965 and 1980. Additionally, the effects of this region of significance indicated that the relationship between professional online image concerns and inappropriate self-disclosure was positive for older respondents. This finding did not provide support for H2b which expected higher professional online image concerns to predict lower levels of inappropriate self-disclosure among older respondents.

Education. H2c was only significant for education scores equal to or below 1.20 (p<.01). In other words, the interaction was significant for all respondents with no high school degree, and a small proportion of the respondents with a high school degree. Additionally, the effects for this region of significance indicated that the relationship between professional online image concerns and 
inappropriate self-disclosure was positive for respondents with low levels of education. Therefore, these findings did not support $\mathrm{H} 2 \mathrm{c}$, which expected higher professional online image concerns to predict lower levels of inappropriate self-disclosure among highly educated respondents.

Work Experience. H2d was significant for two sub-groups in the sample: respondents with an experience score of 1.5 and below $(\mathrm{p}<.01)$, and those with a score of 4.75 and above $(\mathrm{p}<.01)$. In other words, the interaction was significant for all respondents with 1 year of experience or less, in addition to a proportion of respondents with up to 2 years of experience; and for some respondents with 6 to 10 years of experience, in addition to all respondents with 11 years of experience or more. Moreover, the effects of these regions of significance indicated that the interaction was negative for less experienced respondents, but became positive for more experienced respondents. In other words, high professional online image concerns predicted low inappropriate self-disclosure for respondents with low levels of work experience, and higher levels of inappropriate self-disclosure for more experienced respondents. This finding did not support $\mathrm{H} 2 \mathrm{~d}$ which predicted decreased inappropriate self-disclosure with higher levels of work experience.

\section{Discussion and Implications}

Drawing on the theories of hyperpersonal computer-mediated communication, self-efficacy and social exchange, we investigated the relationships between professional online image concerns, social media self-efficacy and social media effectiveness on the one hand, and inappropriate and career-oriented self-disclosures on the other hand. By combining these factors, we perceived self-disclosure as an impression management strategy impacted by how self-efficacious individuals are, driven by the desire to convey a professional image, and employing a computermediated communication channel that facilitates optimized self-presentation. On this online medium, self-disclosure is also a social exchange process in which job seekers who perceive social media as effective job search tools engage in career-oriented self-presentation towards getting a subjective utility in the form of a job opportunity, and abstain from inappropriate selfdisclosure with the purpose of avoiding the subjective risk of exclusion from the recruitment 
process. Hierarchial regression analyses were conducted on a large, diverse dataset of survey responses from employed and unemployed Italian job seekers, and findings are presented below.

The first finding of this study pertained to the non-significant relationship between professional online image concerns and inappropriate self-disclosure. This suggests that while computer-mediated communication faciliates optimized self-presentation, it does not necessarily reduce inappropriate dislosure. This result is in line with previous findings on the 'posting paradox', which showed that awareness of the inappropriateness of self-disclosure did not prevent students from engaging in this behavior (Miller et al., 2010). A possible explanation for this finding is that job seekers may be applying two types of self-presentation strategies: a positive self-presentation that entails selectively revealing socially desirable aspects of oneself; and a honest self-presentation that includes even negative aspects about oneself (J. Kim \& Lee, 2011). Interaction analyses, however, found age, education level and work experience, but not gender, to have differential impacts on the relationship between professional online image concerns and inappropriate self-disclosure. While it was expected that high professional online image concerns combined with older age, high levels of education or more work experience would lead to lower levels of inappropriate self-disclosure, the results did not provide sufficient evidence to support these hypotheses. More particularly, results showed that high professional online image concerns predicted higher levels of inappropriate self-disclosure for older, less educated, and more work experienced respondents. On the other hand, high professional online image concerns predicted lower levels of inappropriate self-disclosure for less work experienced respondents. For the increased inappropriate self-disclosure by older job seekers, this finding is in accordance with a Pew Internet report demonstrating that young adults below 29 were more likely than older users to take steps to limit the amount of personal information available about them online, to delete unwanted comments, and to remove their names from photos (Madden \& Smith, 2010). However, it is not clear why this is the case. It is likely that a certain level of technology illiteracy or unfamiliarity leads to the misuse of social media, and thus to an increase of inadvertent inappropriate self-disclosure by older and less educated job seekers. In terms of work experience, previous studies showed that early-stage employees with less work experience perceived offline networking activities as an important tool for promoting their careers, whereas employees with greater work experience and in later career stages felt that their careers had plateaued, and thus felt that networking was a waste of time and effort (Forret \& Dougherty, 
2001). It is therefore possible that the same applies to online behavior and inappropriate posting, as more experienced employees who have more stable careers and fewer concerns about future employment are more negligent about their professional impression management. Finally, the absence of gender-based differences may be because differences in social media usage, such as broadcasting and self-promotion, are rather associated with the tendency to accept risk than with sex per se (Underwood, Kerlin, \& Farrington-Flint, 2011).

As expected, results showed that high professional online image concerns predicted increased levels of career-oriented self-disclosure on social media. This optimized selfpresentation is facilitiaed by the computer-mediated nature of social media as posited by the hyperpersonal computer-mediated communication theory. It is possible that the anticipation of job seekers to meet and interact recruiters, and to have a long-term relationship with at least one of them as an employer, influences their career-oriented self-disclosure on social media, as was found in the dating context (Gibbs et al., 2006). However, this relationship did not vary with gender, age, education level or work experience. It is possible that the items considered as career-oriented in our study included an implicit minimum disclosure threshold on social media, and that it is widely common to disclose this amount of information by default without necessarily being on the job market. Additionally, since behavior is a joint function of individual differences and situational forces, it is possible that career-oriented self-disclosure is more influenced by implicit or explicit cues provided by external entities regarding the desirability of potential behaviors, or 'situational strength' (Meyer, Dalal, \& Hermida, 2010). In other words, different categories of social media users are probably equally subjected to social and peer pressure to disclose personal and career-oriented information, thus reducing relevant behavioral variance in this construct. On the other hand, what is deemed 'inappropriate' self-disclosure still remains subjective and offers more variance in behaviors and subsequent outcomes.

Social media self-efficacy predicted both inappropriate and career-oriented selfdisclosure as expected. This suggests that job seekers who felt self-efficacious about their social media skills engaged in optimized self-presentation on these websites, but also committed the faux pas of posting inappropriate material as a result of increased use and loss of inhibition. Social media effectiveness in the job search, on the other hand, was a positive predictor of career-oriented self-disclosure as expected, but not of inappropriate posting. This indicates that job seekers seemed to understand the implication of the social contract requiring that they 
disclose career-oriented information about themselves to be able to get the most of social media in their job search. It is possible, however, that some content deemed inappropriate for work environments was still required to honor other social contracts, especially those involving peers.

\subsection{Theoretical Contributions and Practical Implications}

The present study makes several theoretical contributions. First, this study is added to a stream of research that extends, but also challenges, the hyperpersonal model by applying it to new social technologies (Walther, 2011) in the employment context. While the hyperpersonal computermediated communication theory and the social exchange theory served as suitable frameworks to explain the impact of professional online image concerns and the effectiveness of social media in the job search on career-oriented self-disclosure, they did not support the predicted reduced inappropriate self-disclosure. The small variance explained in both types of self-disclosure requires the examination of more predictors, and the use of additional theories. Second, this study tested the theoretical model suggested by (Omarzu, 2000), and provided further empirical support for Misoch's (2015) model which was only tested in a qualitative study using YouTube videos on the subject of self-injury in Germany. As such, the generalizability of these selfdisclosure models is enhanced by applying them to a different context and geographic location, namely employment in Italy.

This study has practical implications for both recruiters and job seekers. Our findings suggest that recruiters need to be cautious while performing social media-based screening. Recruiters might assess certain salient, and mostly seemingly negative, aspects on a candidate's social media profile, and extrapolate future negative work performance indicators from them. However, the lack of sufficient empirical evidence supporting the predictive validity of social media-based screening suggests that this practice could be misleading. It is possible, based on our findings, to positively interpret an individual's inappropriate over-sharing behavior on social media as a high level of social media self-efficacy, which could in return be an indicator of his or her possession of technical, interpersonal and communication skills, deemed by management scholars as crucial managerial skills to organizational achievement (Peterson \& Van Fleet, 2004). As a matter of fact, frequent or greater use of social media is associated with practical computer knowledge (Appel, 2012), innovation, openness to experience, creativity (Correa, Hinsley, \& de Zúñiga, 2010), high levels of social connectedness, and better working memory (Alloway \& 
Alloway, 2012). Cognizant of the riskiness of using social media in screening, some researchers recommended standardizing social media-based assessments, using multiple raters; verifying the accuracy of information obtained from social media (Davison et al., 2012); and developing guidelines regarding the use of social media in the application process to take into account existing practical, legal, and ethical issues (Smith \& Kidder, 2010).

As for job seekers, it is recommended, based on the findings of this study, that they take more caution in handling their self-presentation on social media. While portraying oneself as a drinker, for example, is considered by many young people to be a socially desirable component of identity on social media (Ridout et al., 2012), recruiters expect job applicants to prioritize professional identity concerns online over other potentially competing goals such as identity exploration (Berkelaar, 2014). It should be noted, however, that absence or withdrawal from social media is not a safe option, as this is considered a virtual identity suicide (Stieger, Burger, Bohn, \& Voracek, 2013), which rather exposes job seekers to the risks of being under-branded and misunderstood (Labrecque et al., 2011), being perceived as less committed (Berkelaar \& Buzzanell, 2014), or viewed suspiciously by recruiters (Berkelaar, 2014). With prognostications of the 2020 workplace claiming that people will be hired and promoted in the future based on their reputation capital (Meister \& Willyerd, 2010), and with the professional management of one's image online considered by employers as necessary in career success (Berkelaar, 2014), it is crucial for job seekers as well as employees to closely monitor their impression management and self-presentation on social media.

\section{Limitations and Future Research}

This study is not without limitations. The first limitation pertains to the possibility of having overlooked other relevant confounding aspects. For example, whether job seekers used social media with their real names was not taken into account in this study. It is possible that some respondents use aliases on social media as a way to preserve their privacy (Raynes-Goldie, 2010), and are consequently less concerned about online image and inappropriate self-disclosure. Moreover, it is possible that some respondents augmented their privacy during their job search to prevent potential employers from viewing their personal content (Trottier, 2012). Employment status, however, was taken into account as a possible confounding variable and was not found to be a significant predictor in any of the conducted regression analyses. The second limitation is 
the lack of control for the type of jobs the respondents were looking for, or for the organizational level of the current position of those who were employed. It is thus possible that individuals possessing, or seeking, semi-public positions have greater professional concerns, and that individuals seeking higher positions of power would be taking fewer risks with inappropriate postings.

Several avenues are possible for future research. While the present study used crosssectional self-reported data, no common method variance issues were detected. Future research, however, might further reduce risks of common method variance and social desirability by directly collecting data about the respondents' self-disclosure behaviors from social media, in conjunction with a survey on their perceptions and personality characteristics. It is possible, for instance, to prepare a codebook for a uniform assessment of what makes content inappropriate. Examples of appropriate methodologies for this purpose include a ready-made photographic essay used by Ridout et al. (2012) to gain insight about the portrayal of alcohol-identity on Facebook.

In the present study, the partial loss of control over one's image and reputation on social media was acknowledged by including photo tags in the inappropriate disclosure construct, as well as third-party comments in the career-oriented disclosure construct. By doing so, selfdisclosure and online image management were presented as co-creation processes, especially on social media which are inherently characterized by co-creation (El Ouirdi, El Ouirdi, Segers, \& Henderickx, 2014). Future research is needed to re-examine these constructs in other contexts, with a particular focus on potential cross-cultural differences. 


\section{Appendix A}

Inappropriate self-disclosure (adapted from Peluchette and Karl, 2009, and Karl, Peluchette, and Schlaegel, 2010)

Informal selfie or tagged photo (e.g. wearing a swimsuit)

Controversial selfie / tagged photo (e.g. drinking alcohol)

Comments on controversial topics (e.g. illegal drugs)

Comments on participation in activities which are in violation of university or workplace policy

Career-oriented self-disclosure (inspired by the findings of Zide et al., 2014)

Personal information (e.g. marital status, gender...)

Personality emerging from profile

Pictures

Professional experience

Number of contacts

Hobbies and personal interests

Professional prizes and awards

References and comments posted by others

Content posted

Professional online image concerns (shortened from Miller et al., 2012)

It is important to maintain a professional image online

I work hard to maintain a professional image in my profile

My online image is important to my future

Social media self-efficacy (adapted from Y. Kim and Glassman, 2013)

I can be very effective using social media

I can have a positive impact on the lives' of others through social media

I can offer other people important and interesting information by posting on social media

I can find important and interesting information by reading other people's content on social media 
I can use social media as an effective way of connecting with others

I can communicate very effectively using social media

Social media effectiveness in the job search (measure developed for this study)

Facebook

YouTube

LinkedIn

Twitter

Google+

Blog (Blogger, Wordpress...)

Tumblr

Pinterest

Instagram

Viadeo

Xing 


\section{References}

Alloway, T. P., \& Alloway, R. G. (2012). The impact of engagement with social networking sites (SNSs) on cognitive skills. Computers in Human Behavior, 28(5), 1748-1754.

Appel, M. (2012). Are heavy users of computer games and social media more computer literate? Computers \& Education, 59(4), 1339-1349.

Attrill, A. (2012). Sharing Only Parts of Me: Selective Categorical Self-Disclosure Across Internet Arenas. International Journal of Internet Science, 7(1), 55-77.

Bandura, A. (1977). Self-Efficacy: Toward a Unifying Theory of Behavioral Change. Psychological Review, 84(2), 191-215.

Bandura, A. (2001). Social Cognitive Theory of Mass Communication. In J. Bryant \& D. Zillman (Eds.), Media effects: Advances in theory and research (pp. 121-153). Hillsdale, NJ: Lawrence Erlbaum.

Baron, R. M., \& Kenny, D. A. (1986). The Moderator-Mediator Variable Distinction in Social Psychological Research: Conceptual, Strategic, and Statistical Considerations. Journal of Personality and Social Psychology, 51(6), 1173-1182.

Bartlett, J., Norrie, R., Patel, S., Rumpel, R., \& Wibberley, S. (2014). Misogyny on Twitter. Retrieved from http://www.demos.co.uk/files/MISOGYNY_ON_TWITTER.pdf?1399567516

Bateman, P. J., Pike, J. C., \& Butler, B. S. (2011). To disclose or not: publicness in social networking sites. Information Technology \& People, 24(1), 78-100.

Belk, R. W. (2013). Extended Self in a Digital World. Journal of Consumer Research, 40(3), 477-500.

Berkelaar, B. L. (2014). Cybervetting, Online Information, and Personnel Selection: New Transparency Expectations and the Emergence of a Digital Social Contract. Management Communication Quarterly, 28(4), 479-506.

Berkelaar, B. L., \& Buzzanell, P. M. (2014). Online Employment Screening and Digital Career Capital: Exploring Employers' Use of Online Information for Personnel Selection. Management Communication Quarterly, 1-30.

Brown, V. R., \& Vaughn, E. D. (2011). The Writing on the (Facebook) Wall: The Use of Social Networking Sites in Hiring Decisions. Journal of Business and Psychology, 26(2), 219-225.

Chang, C.-W., \& Heo, J. (2014). Visiting theories that predict college students' self-disclosure on Facebook. Computers in Human Behavior, 30, 79-86. 
Chang, T., \& Hsiao, W.-H. (2014). Time Spent on Social Networking Sites: Understanding User Behavior and Social Capital. Systems Research and Behavioral Science, 31(1), 102-114.

Chen, C.-P. (2013). Exploring Personal Branding on YouTube. Journal of Internet Commerce, 12(4), 332-347.

Chretien, K. C., Greysen, S. R., Chretien, J.-P., \& Kind, T. (2009). Online Posting of Unprofessional Content by Medical Students. JaMa, 302(12), 1309-1315.

Christofides, E., Muise, A., \& Desmarais, S. (2009). Information Disclosure and Control on Facebook: Are They Two Sides of the Same Coin or Two Different Processes? Cyberpsychology \& Behavior, 12(3), 341-345.

Christofides, E., Muise, A., \& Desmarais, S. (2012). Hey Mom, What's on Your Facebook? Comparing Facebook Disclosure and Privacy in Adolescents and Adults. Social Psychological and Personality Science, 3(1), 48-54.

Clark, L. A., \& Roberts, S. J. (2010). Employer's Use of Social Networking Sites: A Socially Irresponsible Practice. Journal of Business Ethics, 95(4), 507-525.

Correa, T., Hinsley, A. W., \& de Zúñiga, H. G. (2010). Who interacts on the Web?: The intersection of users' personality and social media use. Computers in Human Behavior, 26(2), 247-253.

Cronbach, L. J. (1951). Coefficient Alpha and the Internal Structure of Tests. Psychometrika, 16(3), 297-334.

Cropanzano, R., \& Mitchell, M. S. (2005). Social Exchange Theory: An Interdisciplinary Review. Journal of Management, 31(6), 874-900.

Curran, M. J., Draus, P., Schrager, M., \& Zappala, S. (2014). College students and HR professionals: conflicting views on information available on Facebook. Human Resource Management Journal.

Davison, H. K., Maraist, C., \& Bing, M. N. (2011). Friend or Foe? The Promise and Pitfalls of Using Social Networking Sites for HR Decisions. Journal of Business and Psychology, 26(2), 153-159.

Davison, H. K., Maraist, C. C., Hamilton, R. H., \& Bing, M. N. (2012). To Screen or Not to Screen? Using the Internet for Selection Decisions. Employee Responsibilities and Rights Journal, 24(1), 1-21.

Ebnet, N. J. (2012). It Can Do More Than Protect Your Credit Score: Regulating Social Media Pre-Employment Screening With The Fair Credit Reporting Act. Minnesota Law Review. 
Eisinga, R., Grotenhuis, M. Te, \& Pelzer, B. (2013). The reliability of a two-item scale: Pearson, Cronbach or Spearman-Brown? International Journal of Public Health, 58(4), 637-642.

El Ouirdi, M., El Ouirdi, A., Segers, J., \& Henderickx, E. (2014). Social Media Conceptualization and Taxonomy: A Lasswellian Framework. Journal of Creative Communications, 9(2), 107-126.

Elefant, C. (2011). The "Power" of Social Media: Legal Issues \& Best Practices for Utilities Engaging Social Media. Energy Law Journal, 32(1), 1-56.

Eurostat. (2015). Euro area unemployment rate at 11.5\%. Retrieved from http://ec.europa.eu/eurostat/documents/2995521/6454659/3-07012015-APEN.pdf/f4d2866e-0562-49f5-8f29-67e1be16f50a

Forret, M. L., \& Dougherty, T. W. (2001). Correlates of Networking Behavior for Managerial and Professional Employees. Group \& Organization Management, 26(3), 283-311.

Gangadharbatla, H. (2008). Facebook Me: Collective Self-Esteem, Need to Belong, and Internet Self-Efficacy as Predictors of the iGeneration's Attitudes Toward Social Networking Sites. Journal of Interactive Advertising, 8(2), 5-15.

Gazioglu, S., \& Tansel, A. (2006). Job satisfaction in Britain: individual and job related factors. Applied Economics, 38(10), 1163-1171.

Gibbs, J. L., Ellison, N. B., \& Heino, R. D. (2006). Self-Presentation in Online Personals: The Role of Anticipated Future Interaction, Self-Disclosure, and Perceived Success in Internet Dating. Communication Research, 33(2), 152-177.

Hayes, A. F. (2012). PROCESS: A Versatile Computational Tool for Observed Variable Mediation, Moderation, and Conditional Process Modeling, 1-39.

Hayes, A. F., \& Matthes, J. (2009). Computational procedures for probing interactions in OLS and logistic regression: SPSS and SAS implementations. Behavior Research Methods, 41(3), 924-936.

Hocevar, K. P., Flanagin, A. J., \& Metzger, M. J. (2014). Social media self-efficacy and information evaluation online. Computers in Human Behavior, 39, 254-262.

Hogan, B. (2010). The Presentation of Self in the Age of Social Media: Distinguishing Performances and Exhibitions Online. Bulletin of Science, Technology \& Society, 30(6), 377-386.

Hollenbaugh, E. E., \& Ferris, A. L. (2014). Facebook self-disclosure: Examining the role of traits, social cohesion, and motives. Computers in Human Behavior, 30, 50-58. 
Hsu, M.-H., \& Chiu, C.-M. (2004). Internet Self-Efficacy and Electronic Service Acceptance. Decision Support Systems, 38(3), 369-381.

Jackson II, R. L. (2010). Encyclopedia of identity. (R. L. Jackson II, Ed.). SAGE Publications.

Jackson, N., \& Lilleker, D. (2011). Microblogging, Constituency Service and Impression Management: UK MPs and the Use of Twitter. The Journal of Legislative Studies, 17(1), 86-105.

Jiang, L. C., Bazarova, N. N., \& Hancock, J. T. (2011). The Disclosure-Intimacy Link in Computer-Mediated Communication: An Attributional Extension of the Hyperpersonal Model. Human Communication Research, 37(1), 58-77.

Joinson, A. N. (2001). Self-disclosure in computer-mediated communication: The role of selfawareness and visual anonymity. European Journal of Social Psychology, 31(2), 177-192.

Joinson, A. N., \& Paine, C. B. (2007). Self-disclosure, privacy and the Internet. In The Oxford handbook of Internet psychology (pp. 235-250).

Karl, K., Peluchette, J., \& Schlaegel, C. (2010). Who's Posting Facebook Faux Pas? A CrossCultural Examination of Personality Differences. International Journal of Selection and Assessment, 18(2), 174-186.

Kim, J., \& Lee, J.-E. R. (2011). The Facebook Paths to Happiness: Effects of the Number of Facebook Friends and Self-Presentation on Subjective Well-Being. Cyberpsychology, Behavior, and Social Networking, 14(6), 359-364.

Kim, Y., \& Glassman, M. (2013). Beyond search and communication: Development and validation of the Internet Self-efficacy Scale (ISS). Computers in Human Behavior, 29(4), $1421-1429$.

Kirwan, G., \& Mc Guckin, C. (2013). Professional Reputation and Identity in the Online World. International Review of Information Ethics, 19, 47-51.

Ko, H.-C., \& Kuo, F.-Y. (2009). Can Blogging Enhance Subjective Well-Being Through SelfDisclosure? CyberPsychology \& Behavior, 12(1), 75-9.

Kothari, C. R. (2011). Research Methodology: Methods \& Techniques. New Age International.

Labrecque, L. I., Markos, E., \& Milne, G. R. (2011). Online Personal Branding: Processes, Challenges, and Implications. Journal of Interactive Marketing, 25(1), 37-50.

Langenfeld, S. J., Cook, G., Sudbeck, C., Luers, T., \& Schenarts, P. J. (2014). An Assessment of Unprofessional Behavior Among Surgical Residents on Facebook: A Warning of the Dangers of Social Media. Journal of Surgical Education, 1-5. 
Lee, D.-H., Im, S., \& Taylor, C. R. (2008). Voluntary Self-Disclosure of Information on the Internet: A Multimethod Study of the Motivations and Consequences of Disclosing Information on Blogs. Psychology \& Marketing, 25(7), 692-710.

Madden, M., \& Smith, A. (2010). Reputation Management and Social Media. Pew Internet \& American Life Project.

Mathieu, J. E., \& Zajac, D. M. (1990). A Review and Meta-Analysis of the Antecedents, Correlates, and Consequences of Organizational Commitment. Psychological Bulletin, 108(2), 171-194.

Meister, J. C., \& Willyerd, K. (2010). The 2020 Workplace: How Innovative Companies Attract, Develop, And Keep Tomorrow's Employees Today.

Meyer, R. D., Dalal, R. S., \& Hermida, R. (2010). A Review and Synthesis of Situational Strength in the Organizational Sciences. Journal of Management, 36(1), 121-140.

Miller, R., Parsons, K., \& Lifer, D. (2010). Students and Social Networking Sites: The Posting Paradox. Behaviour \& Information Technology, 29(4), 377-382.

Miller, R., Salmona, M., \& Melton, J. (2012). Modeling Student Concern for Professional Online Image. Journal of Internet Social Networking \& Virtual Communities, 2012, 1-13.

Misoch, S. (2015). Stranger on the internet: Online self-disclosure and the role of visual anonymity. Computers in Human Behavior, 48, 535-541.

Moon, Y. (2000). Intimate Exchanges: Using Computers to Elicit Self-Disclosure from Consumers. Journal of Consumer Research, 26(4), 323-339.

Moreno, A., Navarro, C., Tench, R., \& Zerfass, A. (2015). Does social media usage matter? An analysis of online practices and digital media perceptions of communication practitioners in Europe. Public Relations Review.

Ness, G. L., Sheehan, A. H., Snyder, M. E., Jordan, J., Cunningham, J. E., \& Gettig, J. P. (2013). Graduating Pharmacy Students' Perspectives on E-Professionalism and Social Media. American Journal of Pharmaceutical Education, 77(7), 146.

Newness, K., Steinert, J., \& Viswesvaran, C. (2012). Effects of Personality on Social Network Disclosure: Do Emotionally Intelligent Individuals Post Inappropriate Content? Psychological Topics, 21, 473-486.

Omarzu, J. (2000). A Disclosure Decision Model: Determining How and When Individuals Will Self-Disclose. Personality and Social Psychology Review, 4(2), 174-185. 
Peluchette, J., \& Karl, K. (2008). Social Networking Profiles: An Examination of Student Attitudes Regarding Use and Appropriateness of Content. CyberPsychology \& Behavior, 11(1), 95-97.

Peluchette, J., \& Karl, K. (2009). Examining Students' Intended Image on Facebook: "What Were They Thinking?!" Journal of Education for Business, 85(1), 30-37.

Peterson, T. O., \& Van Fleet, D. D. (2004). The ongoing legacy of R.L. Katz: An updated typology of management skills. Management Decision, 42(10), 1297-1308.

Putzke, J., Fischbach, K., Schoder, D., \& Gloor, P. A. (2014). Cross-Cultural Gender Differences in the Adoption and Usage of Social Media Platforms - An Exploratory Study of Last.FM. Computer Networks.

Raynes-Goldie, K. (2010). Aliases, creeping, and wall cleaning: Understanding privacy in the age of Facebook. First Monday, 15(1).

Ridout, B., Campbell, A., \& Ellis, L. (2012). "Off your Face(book)": Alcohol in online social identity construction and its relation to problem drinking in university students. Drug and Alcohol Review, 31(1), 20-26.

Root, T., \& McKay, S. (2014). Student Awareness of the Use of Social Media Screening by Prospective Employers. Journal of Education for Business, 89(4), 202-206.

Schouten, A. P., Valkenburg, P. M., \& Peter, J. (2007). Precursors and Underlying Processes of Adolescents' Online Self-Disclosure: Developing and Testing an "Internet-AttributePerception" Model. Media Psychology, 10(2), 292-315.

Schwartz, H. A., Eichstaedt, J. C., Kern, M. L., Dziurzynski, L., Ramones, S. M., Agrawal, M., ... Ungar, L. H. (2013). Personality, Gender, and Age in the Language of Social Media: The Open-Vocabulary Approach. PloS One, 8(9), e73791.

Shibchurn, J., \& Yan, X. (2015). Information disclosure on social networking sites: An intrinsicextrinsic motivation perspective. Computers in Human Behavior, 44, 103-117.

Slovensky, R., \& Ross, W. H. (2012). Should human resource managers use social media to screen job applicants? Managerial and legal issues in the USA. Info, 14(1), 55-69.

Smith, W. P., \& Kidder, D. L. (2010). You've been tagged! (Then again, maybe not): Employers and Facebook. Business Horizons, 53(5), 491-499.

Snyder, J., Carpenter, D., \& Slauson, G. J. (2007). MySpace.com - A Social Networking Site and Social Contract Theory. Information Systems Education Journal, 5(2), 1-11.

Special, W. P., \& Li-Barber, K. T. (2012). Self-disclosure and student satisfaction with Facebook. Computers in Human Behavior, 28(2), 624-630. 
Stieger, S., Burger, C., Bohn, M., \& Voracek, M. (2013). Who Commits Virtual Identity Suicide? Differences in Privacy Concerns, Internet Addiction, and Personality Between Facebook Users and Quitters. Cyberpsychology, Behavior and Social Networking, 16(9), 629-634.

Stoughton, J. W., Thompson, L. F., \& Meade, A. W. (2013). Examining Applicant Reactions to the Use of Social Networking Websites in Pre-Employment Screening. Journal of Business and Psychology, 1-16.

Suler, J. (2004). The Online Disinhibition Effect. Cyberpsychology \& Behavior, 7(3), 321-326.

Trottier, D. (2012). Interpersonal Surveillance on Social Media. Canadian Journal of Communication, 37(2), 319-332.

Tufekci, Z. (2007). Can You See Me Now? Audience and Disclosure Regulation in Online Social Network Sites. Bulletin of Science, Technology \& Society, 28(1), 20-36.

Underwood, J. D. M., Kerlin, L., \& Farrington-Flint, L. (2011). The lies we tell and what they say about us: Using behavioural characteristics to explain Facebook activity. Computers in Human Behavior, 27(5), 1621-1626.

Utz, S. (2014). The function of self-disclosure on social network sites: not only intimate, but also entertaining self-disclosure increases the feeling of connection. Computers in Human Behavior, 45, 1-10.

Vicknair, J., Elkersh, D., Yancey, K., \& Budden, M. C. (2010). The Use Of Social Networking Websites As A Recruiting Tool For Employers. American Journal of Business Education, $3(11), 7-12$.

Walther, J. B. (1996). Computer-Mediated Communication Impersonal, Interpersonal, and Hyperpersonal Interaction. Communication Research, 23(1), 3-43.

Walther, J. B. (2007). Selective self-presentation in computer-mediated communication: Hyperpersonal dimensions of technology, language, and cognition. Computers in Human Behavior, 23(5), 2538-2557.

Walther, J. B. (2011). Theories of Computer-Mediated Communication and Interpersonal Relations. The Handbook of Interpersonal Communication, 443-479.

West Coast LEAF. (2014). \#CyberMisogyny: Using and strengthening Canadian legal responses to gendered hate and harassment online.

Wrench, J. S., \& Punyanunt-Carter, N. M. (2007). The Relationship between ComputerMediated-Communication Competence, Apprehension, Self-Efficacy, Perceived Confidence, and Social Presence. Southern Communication Journal, 72(4), 355-378. 
Young, A. L., \& Quan-Haase, A. (2009). Information Revelation and Internet Privacy Concerns on Social Network Sites: A Case Study of Facebook. In Proceedings of the fourth international conference on Communities and technologies (pp. 265-273).

Zhao, S., Grasmuck, S., \& Martin, J. (2008). Identity construction on Facebook: Digital empowerment in anchored relationships. Computers in Human Behavior, 24(5), 1816-1836.

Zhao, X., Salehi, N., Naranjit, S., Alwaalan, S., Voida, S., \& Cosley, D. (2013). The Many Faces of Facebook: Experiencing Social Media as Performance, Exhibition, and Personal Archive. In Proceedings of the SIGCHI Conference on Human Factors in Computing Systems (pp. 1$10)$.

Zide, J., Elman, B., \& Shahani-Denning, C. (2014). LinkedIn and recruitment: how profiles differ across occupations. Employee Relations, 36(5), 583-604. 